\section{A constituição do sujeito surdo na cultura guarani-kaiowá: os processos próprios de interação e comunicação na família e na escola ${ }^{1}$ The subject constitution inside deaf culture guarani-kaiowá: own interaction processes and communication in family and school}

\author{
Luciana Lopes Coelho* \\ Marilda Moraes Garcia Bruno**
}

Resumo: A interface da educação especial na educação indígena é um campo novo e complexo de investigação, traça fronteiras ainda não definidas entre dois campos de conhecimento em constituição. Este trabalho investigou a constituição do sujeito surdo na cultura Guarani-Kaiowá e os processos de interação e comunicação na família e na escola. As análises permitiram situar o sujeito indígena surdo em uma cultura diferenciada e compreendermos as relações estabelecidas entre as culturas em contato e as línguas usadas nas aldeias estudadas. Identificaram-se ainda as possibilidades e as necessidades específicas e de comunicação no ambiente familiar e escolar.

Palavras chave: Educação Escolar Indígena. Educação Especial. Surdez.

Abstract: The encounter of special needs education in indigenous education is a complex new field of research, there are no defined boundaries between the two fields of knowledge coming into being. This study investigated the constitution of the deaf culture GuaraniKaiowa and the processes of interaction and communication within the family and school. The analysis allows the subject to place indigenous deaf in a different culture and understand the relations between the cultures as they come into contact with the languages used in the villages studied. It also identified opportunities and specific needs in communication both in the family and school.

Key words: Indigenous Education. Special Education. Deafness.

${ }^{1}$ Texto apresentado originalmente na $35^{\mathrm{a}}$ Reunião Anual da ANPED - Porto de Galinhas, PE - 21 a 24 de outubro de 2012 e redimensionado com atualização das discussões teóricas.
* Professora Assistente, Universidade Federal da Grande Dourados (UFGD).E-mail: Luciana.lopescoelho@ hotmail.com

** Professora Adjunta Universidade Federal da Grande Dourados (UFGD). E-mail: Marildabruno@ufgd.edu.br

$$
\text { Tellus, ano 13, n. 25, p. 127-144, jul./dez. } 2013
$$

Campo Grande, MS 


\section{Introdução}

Nestes últimos anos, tanto a Educação Escolar Indígena quanto os Estudos Surdos, com crescente produção científica na área da linguística e da educação, vêm se esforçando para delinear um vigoroso campo de debate acerca da cultura, dos processos próprios de linguagem e formas diferenciadas de aprendizagem. Delimitar os objetivos, os métodos e os limites de um estudo dessa natureza não é tarefa fácil, parece-nos que deve ser feito a partir dos objetos e das práticas culturais entendidas como significações que as comunidades indígenas atribuem ao fenômeno surdez, às palavras e às ações cotidianas.

Observamos nos dias atuais que a realidade educacional indígena está vivenciando um processo de mudança, devido à reconfiguração do seu sistema de ensino. Durante décadas o Estado brasileiro empregou propostas homogêneas de educação com um único sentido: o de integrar a população indígena à sociedade brasileira (GRUPIONI, 2008). No entanto, recentemente, o Estado brasileiro tem regulamentado a proposta de educação diferenciada para esses grupos. Independente da motivação que levou o Estado a fazê-lo, esse esforço reflete que estão acontecendo negociações entre os gestores da educação e os representantes do movimento indigenista, grupo que reivindica a consolidação dos seus direitos e a legitimação das suas práticas educacionais alternativas.

Sendo assim, também é recente a preocupação com a organização da escola indígena para o atendimento de todas as crianças, incluindo as que possuem uma diferença quer sensorial, física, cognitiva, quer linguística. A inclusão dessas pessoas no processo de escolarização não acontece sem a ruptura de paradigmas e mudanças nas representações e concepções sobre as diferenças. Se antes as crianças que possuíam 'anomalias' não sobreviviam em algumas comunidades (de acordo com os pesquisadores Graciela Chamorro e Bartolomeu Meliá2, isso ocorria e ainda ocorre em muitas aldeias), hoje elas não apenas têm alguma expectativa de vida como estão sendo inseridas na escola. Os motivos que levaram algumas comunidades a uma mudança de concepção sobre as diferenças podem ser muitos, e isso nos provoca a investigá-los. No entanto o fato é que as crianças com deficiência estão chegando cada vez mais aos espaços escolares, e os professores e demais profissionais da educação procuram formas mais adequadas de transmitir saberes e impulsionar a aprendizagem desses estudantes.

Sob a perspectiva dos estudos culturais, busca-se neste trabalho assumir uma postura investigativa e crítica frente às propostas de educação especial para os índios surdos do nosso país, considerando que a língua e as representações sociais sobre a surdez assumem um papel determinante na

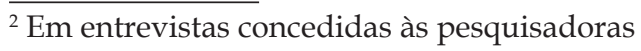


construção de significados e identidades. Para Hall (2006, p. 61-62), a cultura de um povo se constitui de dispositivos discursivos que tentam representar a diferença como unidade ou identidade, na tentativa de formar sujeitos com semelhantes identidades, falantes de uma mesma língua, que reproduzem e transmitem seus 'valores compartilhados'. Por essa razão, entendemos que as políticas para a inclusão de pessoas surdas nas escolas indígenas não devem ser impostas sem antes realizarmos um diálogo com a comunidade indígena e apreendermos os significados da surdez para esse grupo.

Consideramos a complexidade que envolve a discussão de tal temática, porém importa-nos contribuir com a proposta da escola diferenciada indígena e as possibilidades dessa instituição tornar-se acessível a todas as pessoas da comunidade, considerando as culturas e os sistemas próprios de comunicação e aprendizagem das pessoas indígenas surdas.

A pesquisa que subsidiou o recorte deste artigo teve como objetivo investigar a constituição do sujeito surdo na cultura Guarani-Kaiowá e a compreender os processos de interação e comunicação na família e na escola. Nesse percurso, buscamos conhecer a concepção da surdez na cultura GuaraniKaiowá e os seus impactos no processo de socialização, além de identificar os processos próprios de comunicação, verificando a presença de sinais caseiros utilizados na comunicação com a família e a escola e/ou a existência de uma língua de sinais emergentes.

O foco do estudo foram os processos culturais de comunicação e interação dos estudantes indígenas surdos nas comunidades Guarani-Kaiowá dos municípios que compõem a região sul do estado de Mato Grosso do Sul: Amambai, Paranhos e Coronel Sapucaia. O estado de Mato Grosso do Sul possui a segunda maior população indígena do país, o que corresponde a aproximadamente 73.000 indígenas, e os municípios estudados apresentam os maiores indicadores de surdez.

Buscou-se compreender o contexto cultural e linguístico das pessoas indígenas surdas dos municípios envolvidos, considerando como ponto de partida o contexto cultural, concebido como o conjunto de crenças da comunidade, as relações dos indígenas dessas comunidades com as pessoas surdas, os valores familiares e sociais e as concepções da comunidade acerca do fenômeno da surdez. Entende-se que o trabalho etnográfico, ao contrário das investigações que buscam regularidades, é feito por meio de "traduções das construções simbólicas localistas e imediatas da cultura 'nativa', correspondentes à consciência prática e discursiva dos autóctones sobre as suas condições sociais de existência" (CARIA, 2004, p. 14).

Nesse percurso, em contato com a comunidade, as famílias e as escolas, foi possível mapear os indicadores relativos à presença de crianças e de jovens indígenas com surdez. 
Os profissionais da educação escolar indígena, os agentes da saúde indígena e a liderança política, pessoas que, de alguma forma, compõem a comunidade indígena ou trabalham nela, foram informantes sobre a convivência com pessoas surdas e a experiência na atuação junto a esses alunos na escola indígena e na comunidade.

As informações dos profissionais que convivem com pessoas surdas nas aldeias indígenas foram essenciais para a compreensão da situação dessas pessoas no cotidiano, das especificidades linguísticas e dos significados da surdez elaborados no contexto cultural das comunidades estudadas, aspectos que serão discutidos a seguir.

\section{A palavra e a fala como constituidores do sujeito na cultura guarani- -kaiowá}

Em seu sistema de crenças, os povos Guarani possuem elementos que se distinguem das crenças da maioria da população do país. A 'religião' desse grupo está fundamentada na palavra, cujo termo que a designa em guarani $\left(\tilde{n} e^{\prime} e\right.$, ayvu e $\left.\tilde{a}\right)$ pode significar também voz, fala, linguagem, idioma, alma, nome, vida, personalidade e origem (CHAMORRO, 2008).

Essa palavra está presente no sujeito desde o nascimento. Ela é 'invocada' ao se nomear uma criança, e isso determinará a sua personalidade e a identificação com o grupo familiar. A palavra também teria o poder de 'restaurar a vida' de uma pessoa doente (restaurar-lhe a palavra). Para os Guarani, os males e as doenças são resultados da não verbalização dos sentimentos que nos perturbam (MELIÁ, 2011). O fato de 'possuir a palavra' faz com que o sujeito 'vivo' se diferencie dos que estão doentes, mortos ou que não possuem um "nome divinizador" (CHAMORRO, 2008, p. 56).

O termo 'bem viver' (teko porã), para Meliá (2011), representa o modo de ser dos Guarani, seu sistema de vida, seus costumes, que são determinados pela capacidade que o sujeito possui para dialogar com o outro, de expressarse. De acordo com a crença desse povo, a inspiração para a palavra surge da relação com os deuses. Porém é no diálogo entre dois indivíduos que ela se 'constrói' dia a dia. Ainda de acordo com Meliá, “[...], o 'bem viver guarani' começa pela fala, se você não consegue falar com o outro você não consegue viver bem" (informação verbal ${ }^{3}$ ). As relações entre o grupo são baseadas fortemente no diálogo e na comunicação oral.

Visualizamos essas concepções da comunidade indígena nas falas dos familiares de pessoas surdas e profissionais indígenas que atuam

\footnotetext{
${ }^{3}$ Informação fornecida por Bartolomeu Meliá durante palestra ministrada na Universidade Federal da Grande Dourados (UFGD), em abril de 2011, cujo tema foi: Teko Porã: modo de vida guarani. 
nas aldeias. A origem das deficiências entre a comunidade é um assunto delicado; sobre isso um professor comenta: "Porque o indio não é normal ter surdo, mudo, esse problema de vistas que vocês falaram pra gente [...] então deve ter alguma coisa aí; talvez a água, não sei o que é" (P1).

Pesquisas na área da saúde apontam que, de fato, muitos fatores externos podem contribuir com o nascimento de pessoas com deficiência, tais como doenças maternas crônicas, doenças infecciosas, intoxicações, desnutrição etc. De acordo com relatos de pessoas da comunidade, os indígenas que residem nas aldeias sofreram e ainda sofrem com problemas como a falta de alimentação adequada, falta de atendimento na área da saúde, dificuldades de acesso aos centros de tratamento de saúde e falta de informações sobre higiene e prevenção de doenças, além de outros problemas. Isso pode ser relevante para a análise dos dados sobre a incidência de pessoas com deficiência nas comunidades indígenas.

No entanto, ao afirmar que o nascimento de pessoas com deficiência não é algo natural entre os Guarani, podemos inferir dos relatos dos indígenas desse grupo que eles se consideram pertencentes a uma cultura original, que os identifica enquanto grupo étnico diferente dos grupos urbanos. $\mathrm{O}$ conjunto de crenças dessas comunidades inclui a crença de que a constituição dos indivíduos seria determinada por entidades metafísicas, e, por isso, as pessoas com deficiência não seriam 'originadas' da mesma forma que as outras. Sobre isso, outro professor relata as explicações que o seu avô e sua mãe davam para esse fenômeno:

Quando você vê uma pessoa assim (com deficiência) você não tem paciência com ele, maltrata ele, tira sarro nele, então depois que casa, uma parte dos castigos vem disso. A outra é a mulher que faz relação sexual assim, não em casa, escondido. Daí pega o mitã'gae ao invés de pegar o guyrá. [...] Então, como castigo ele (o filho) vem em forma de pessoa com necessidades especiais. [...] Outro ponto é a mulher que aborta muito. Ela manda o ayou porá (espírito bom) embora várias vezes, aí por último vem o mitã'gae por duas coisas: pra matar a mulher ou pra fazer ela, assim, amar essas pessoas. [...] (P3)

Em outros relatos também percebemos explicações semelhantes:

Um senhor de idade (indígena) falou que a criança vem assim, porque foi feito anteriormente alguma coisa errada, e deu castigo. (V.)

Bom, a mãe falou que é por não escutar, né. A cultura é assim; não obedeceu, comeu alguma coisa que prejudicou a criança. (A.S. 2)

Sempre que vêm essas pessoas surdo, mudo, com deficiência intelectual, física, é a culpa sempre do pai e da mãe por descumprir a regra da educação tradicional. [...] Pra nós, não consideramos pessoas deficientes. Existem vários tipos de pessoas, estrutura de pessoas que vem de vários deuses, de vários segmentos. Quando a pessoa vem de um deus 
que não conseguiu fazer perfeito, igual o que o deus sol faz, aí sai essas deficiências. (D.)

$\mathrm{Na}$ fala dos profissionais, percebe-se que não há consenso, mas, ao contrário, existem várias e diferentes explicações acerca do fenômeno da deficiência entre os indígenas. Isso se deve à transformação de costumes e hábitos que acontece nas comunidades.

A surdez para as comunidades Guarani tradicionais representa um fator determinante na assimilação/construção de uma identidade Guarani. Sem a possibilidade de comunicação e expressão por meio da palavra e da fala, o sujeito surdo pode, em alguns contextos, não ser reconhecido pela comunidade como pertencente a ela. Esse sujeito é, muitas vezes, visto pela comunidade pesquisada como ser que se originou de forma diferente das demais pessoas. Sabemos que essa questão precisa ser mais bem investigada e de forma transdisciplinar, considerando que existem muitos fatores envolvidos no estudo das concepções da cultura Guarani.

\section{A pessoa surda e a relação com os pais e responsáveis}

Vimos que as diferentes concepções e modos de lidar com o fenômeno da deficiência têm passado por mudanças dentro da comunidade indígena. Isso também foi observado na fala dos familiares dos jovens indígenas surdos. Para essas famílias, possuir em seu meio uma pessoa com deficiência é uma questão complexa, assim como também o é para todas as famílias das áreas urbanas.

Sabemos que, historicamente, as pessoas com alguma deficiência foram discriminadas por suas características, que diferem das da maioria das pessoas, em diversas sociedades. Com o aumento das pesquisas sobre as deficiências nas áreas médicas e psicológicas, podemos vislumbrar uma maior compreensão das características dos sujeitos que possuem algum tipo de deficiência. Hoje entendemos que a aceitação da diferença passa não apenas por questões culturais, mas também pelo acesso a informações sobre os sujeitos e sobre a inclusão.

O Quadro 1 indica a idade, a etnia, o diagnóstico, a aldeia e o município onde habitam as pessoas com surdez das comunidades Guarani. 


\begin{tabular}{|c|c|c|c|c|}
\hline Nome & Idade & Cidade/Aldeia & Sexo & Observação \\
\hline K. & 12 & $\begin{array}{l}\text { Amambai, } \\
\text { Aldeia Amambai }\end{array}$ & Feminino & $\begin{array}{l}\text { Com diagnóstico médico - Surdez } \\
\text { parcial. Utiliza aparelho auditivo e } \\
\text { está na escola. }\end{array}$ \\
\hline A. & 19 & $\begin{array}{l}\text { Amambai, } \\
\text { Aldeia Amambai }\end{array}$ & Masculino & $\begin{array}{l}\text { Sem diagnóstico médico. Utiliza } \\
\text { sinais caseiros para se comunicar. } \\
\text { Não está na escola, parou no } 4^{\circ} \text { ano. }\end{array}$ \\
\hline D. & 24 & $\begin{array}{l}\text { Amambai, } \\
\text { Aldeia Amambai }\end{array}$ & Masculino & $\begin{array}{l}\text { Com diagnóstico médico - Surdez } \\
\text { severa. Utiliza sinais caseiros para } \\
\text { se comunicar. Nunca frequentou a } \\
\text { escola. }\end{array}$ \\
\hline S. & 12 & $\begin{array}{l}\text { Paranhos, } \\
\text { Aldeia Paraguassu }\end{array}$ & Feminino & $\begin{array}{l}\text { Sem diagnóstico médico. Utiliza } \\
\text { sinais caseiros para se comunicar. } \\
\text { Está na escola. }\end{array}$ \\
\hline I. & 6 & $\begin{array}{l}\text { Coronel Sapucaia, } \\
\text { Aldeia Taquaperi }\end{array}$ & Masculino & $\begin{array}{l}\text { Com diagnóstico médico - Surdez } \\
\text { profunda. Utiliza sinais caseiros } \\
\text { para se comunicar. Não está na } \\
\text { escola }\end{array}$ \\
\hline C. & 10 & $\begin{array}{l}\text { Coronel Sapucaia, } \\
\text { Aldeia Taquaperi }\end{array}$ & Masculino & $\begin{array}{l}\text { Com diagnóstico médico - Surdez } \\
\text { severa. Não utiliza sinais caseiros } \\
\text { para se comunicar. Está na escola. }\end{array}$ \\
\hline E. & 30 & $\begin{array}{l}\text { Coronel Sapucaia, } \\
\text { Aldeia Taquaperi }\end{array}$ & Feminino & $\begin{array}{l}\text { Com diagnóstico médico - Surdez } \\
\text { parcial unilateral. Não utiliza } \\
\text { sinais caseiros para se comunicar. } \\
\text { Nunca frequentou a escola. }\end{array}$ \\
\hline J. & 4 & $\begin{array}{l}\text { Coronel Sapucaia } \\
\text { Aldeia Taquaperi }\end{array}$ & Feminino & $\begin{array}{l}\text { Com diagnóstico médico - Surdez } \\
\text { leve. Tem deficiências múltiplas. } \\
\text { Não está na escola. }\end{array}$ \\
\hline
\end{tabular}

Quadro 1 - Identificação das pessoas com surdez. Fonte: COELHO, 2011.

Os registros mostram sete pessoas identificadas como surdas ou com algum grau de deficiência auditiva (algumas possuíam laudo médico, outras foram avaliadas apenas funcionalmente). Destas, a maioria apresentou pouco ou nenhum domínio da língua falada na sua comunidade. Apenas duas (K. e C.) se comunicam oralmente e demonstram dominar a língua guarani satisfatoriamente. Observou-se que quatro pessoas identificadas não estão na escola, apesar de seus familiares julgarem importante, e as que estão matriculadas frequentam turmas de crianças com idades inferiores à delas. Nas comunidades indígenas pesquisadas, quando questionamos os familiares sobre os possíveis motivos de a pessoa nascer surda, eles dizem desconhecer os motivos. Eles falam muito pouco sobre o assunto: 
Não sei, não tem ninguém que seja assim na família [...] ela nasceu assim mesmo, o médico disse que ela tem um problema no ouvido. (R3)

Depois da caxumba, ele parou de conversar, começou a ficar só no 'aceno' (R1)

Possivelmente essas mães e/ou outros familiares conhecem as concepções sobre as deficiências compartilhadas pela comunidade. No entanto, com os pesquisadores não indígenas, elas utilizam as explicações oriundas dos médicos e agentes de saúde das aldeias. Nas respostas, as explicações curtas e as negações evidenciam um processo de silenciamento sobre esse assunto, talvez porque as deficiências e suas causas sejam relacionadas pela comunidade a castigos, punições ou consequência de maus tratos, o que torna o tema constrangedor para a família.

Cabe ressaltar que esses pais não conheciam o entrevistador e muito provavelmente não sentiram confiança para abordar tal assunto, seja porque faltou entendimento pleno sobre o que se queria saber, receio de não dizer aquilo que o entrevistador gostaria de ouvir, ou receio de dizer algo errado e ser criticado pela comunidade, pelas autoridades políticas e religiosas (em comunidades tradicionais, para falar é necessário conhecer o assunto profundamente).

Solicitou-se aos pais e demais familiares que explicassem as características próprias das pessoas surdas e as formas de comunicação utilizadas por elas no contexto familiar:

Ela percebe a mexida dos lábios, presta muita atenção no que falamos. Usamos gestos pra ela saber. (R2)

Com gesto. Ele não conversa como a gente aqui, é só por gesto. A gente conversa assim, com a palavra com ele, né. Ele não entende a nossa conversa e não responde do jeito que a gente fala. (R1)

Às vezes ela fica brava quando não entendem. Quando acaba a pilha do aparelho, ela fica nervosa [...] Tem que falar bem alto com ela. (R3)

Quando grita pra ela, aí escuta. E ela também não fala nenhuma palavra. [...] Ela usa senha. Para chamar ela tem que fazer a senha assim, ó, tem que mostrar. (R6)

Ele é nervoso. Quando quer alguma coisa, ele bate assim nas coisas, ele não é bom assim da cabeça. [...] tem hora que ele é surdo. (R7)

Não, não ouve. Só conversa assim ... tem que mostrar com as mãos. (R8)

Os relatos indicam que as pessoas surdas se expressam por meio da comunicação gestual e compreendem melhor quando seus familiares a utilizam, mesmo quando há resquícios de audição. Essa comunicação (utilizando gestos simples, sinais icônicos e expressões faciais) não possibilita o diálogo satisfatório, com a transmissão de informações complexas, em muitos casos analisados. De acordo com as linguistas Quadros e Karnopp (2004, p. 30), as 
línguas de sinais são consideradas pela linguística como línguas naturais ou como sistema linguístico legítimo. Porém a realização de alguns sinais icônicos não representa uma língua, pois não possui “[...] um sistema abstrato de regras finitas, as quais permitem a produção de um número ilimitado de frases" (QUADROS; KARNOPP, 2004, p. 30).

Nesse sentido, infere-se que os surdos indígenas das comunidades pesquisadas não possuem uma língua de convenção e, por essa razão, não estão se desenvolvendo e apreendendo o mundo da mesma maneira que as pessoas ouvintes. A compreensão do mundo está limitada pela dificuldade de se aprender a língua oral da família, que é usuária do guarani, e de desenvolver uma língua de sinais naturalmente em seu ambiente. Essa barreira linguística acarreta consequências para o desenvolvimento afetivo, social e cognitivo da pessoa surda (SKLIAR, 2009; QUADROS, 1997). A comunicação nos ambientes familiares pesquisados está restrita à troca de informações simples e relacionadas ao suprimento das necessidades básicas do surdo, excluindo do diálogo informações complexas, abstratas ou que necessitem de uma forma mais elaborada para transmissão.

De acordo com as linguistas Ronice Quadros e Lodenir Karnopp, “[...] forças lingüísticas e sociolingüísticas tendem a inibir a natureza icônica dos sinais, tornando-os mais arbitrários através dos tempos" (QUADROS; KARNOPP, 2004, p. 33). Assim, entende-se que os jovens e as crianças pesquisados não possuem uma língua de convenção, em virtude de o ambiente em que vivem não permitir o contato com outras pessoas com a mesma condição, que utilizem os sinais na comunicação, o que lhes propiciaria o aumento do léxico e o estabelecimento de regras gramaticais.

Muitos sinais utilizados por esses sujeitos não são compreensíveis para os familiares que convivem com eles, o que gera angústia, como vemos nos relatos:

Ela olha na boca das pessoas e tenta entender o que falam. Ela mostra com a mão as coisas, só que eu não consigo entender o que ela quer. [...] Ninguém sabe, ninguém entende. (R6)

Quando ele precisa, ele mostra pra mim nos dedos. A mãe dele não sabia, não entendia. (R5)

Observou-se que as concepções das famílias sobre a surdez dos filhos interferem no encaminhamento e na tomada de atitudes que beneficiariam essas crianças. Muitos responsáveis entrevistados demonstram acreditar que essas pessoas são incapazes de aprender, motivo que, na maioria das vezes, os leva a não as matricularem na escola:

Ela nunca estudou porque ... ela não presta assim pra estudar. (R10)

Ele nunca foi pra escola porque a mãe viu ele assim, surdo, não falando mais, e diz que não tem como praticar a escola. [...] Diz que ele não tem 
capacidade de estudar, porque ele é surdo, não consegue nem se comunicar com os outros, né. Ela tinha medo de ficarem prejudicando ele. (R9)

Ele faz tempo que estuda, mas ele não sabe as coisas, a cabeça dele não é boa. (R7)

Percebeu-se que, apesar das concepções limitantes e das dificuldades para se comunicar com as pessoas surdas, o ambiente familiar se mostrou acolhedor às diferenças, pois todas as pessoas observadas estavam integradas e compartilhavam a casa, alimentos e vestimentas.

\section{A comunicação e as relações no ambiente escolar}

A educação escolar indígena é uma questão polêmica entre os antropólogos, linguistas, pedagogos e outros profissionais que pesquisam as sociedades indígenas. As diferenças culturais e linguísticas dessa população têm sido utilizadas para defender que o ensino para esses povos não deve ser concebido nos moldes da cultura urbana ocidental.

A educação das crianças e jovens indígenas nas culturas Guarani e Kaiowá, tradicionalmente, fica sob a responsabilidade da família extensa (que inclui avós, pais, tios e irmãos) e é efetuada no contexto familiar. O objetivo desse ensino é a perpetuação da ordem social estabelecida, ou seja, a conformação do sujeito ao grupo, porém desenvolvendo a capacidade de se realizar como pessoa e servir ao coletivo como um todo.

Sabe-se que hoje a realidade educacional indígena está em processo de mudança. Recentemente, a proposta de educação aceita como a mais adequada às comunidades indígenas é a da escola diferenciada. Observa-se que essas e outras propostas ainda carregam as marcas de um tempo de colonização e controle das comunidades indígenas por parte do Estado brasileiro (GRUPIONI, 2008). Contudo movimentos indigenistas, com o apoio de pesquisadores e professores da área, lutam para que esse ensino institucionalizado priorize a língua materna indígena no lócus escolar, valorize a diferença cultural, legitime as práticas educacionais alternativas próprias da comunidade indígena, bem como permita o acesso a outros saberes e conhecimentos produzidos pela humanidade. A esse respeito, as autoras Nascimento e Vinha (2007) comentam:

As conquistas legais permitem constatar que os indígenas estão amparados pela legislação, estão motivados pelas suas organizações sociais e políticas e movidos pelas necessidades geradas pela história de contato e os processos de hibridação. Motivados pela quebra do monopólio tutelar exercido pelo Estado, os indígenas estão com os horizontes abertos para a auto-gestão. (NASCIMENTO; VINHA, 2007, p. 12)

Dessa forma, as comunidades indígenas e suas diferenças culturais precisam ser consideradas nas tentativas de implantação de um modelo de 
educação especial e atendimento às pessoas com deficiência nas escolas das aldeias. A autogestão da educação especial e o diálogo intercultural positivo são medidas que precisam ser encorajadas e garantidas.

$\mathrm{Na}$ escola, o problema da comunicação se intensifica, uma vez que os conteúdos ministrados são transmitidos por meio da língua oral e a aprendizagem requerida dos estudantes é o domínio de, no mínimo, duas línguas (a língua guarani e a língua portuguesa). Diante dessa realidade linguística, o ensino oferecido aos alunos surdos esbarra nos problemas de comunicação dentro da sala de aula, entre alunos ouvintes e surdos e alunos surdos e professores ouvintes.

No Quadro 2, indicam-se os profissionais que atuam nas aldeias pesquisadas com pessoas surdas.

\begin{tabular}{|c|c|c|c|}
\hline $\begin{array}{c}\text { Inicial do } \\
\text { Nome/Código }\end{array}$ & $\begin{array}{l}\text { Município/ } \\
\text { Aldeia }\end{array}$ & Sexo & Informações Relevantes \\
\hline $\mathrm{H}(\mathrm{P} 1)$ & $\begin{array}{l}\text { Paranhos } \\
\text { Paraguassu }\end{array}$ & Masculino & $\begin{array}{l}\text { Professor nas séries iniciais da } \\
\text { escola diferenciada indígena que já } \\
\text { ministrou aulas aos alunos surdos. }\end{array}$ \\
\hline $\mathrm{J}(\mathrm{P} 2)$ & $\begin{array}{l}\text { Paranhos } \\
\text { Paraguassu }\end{array}$ & Feminino & $\begin{array}{l}\text { Professor nas séries iniciais da } \\
\text { escola diferenciada indígena } \\
\text { ministra aula à estudante surda. }\end{array}$ \\
\hline $\mathrm{D}(\mathrm{P} 3)$ & $\begin{array}{c}\text { Amambai } \\
\text { Limão Verde }\end{array}$ & Masculino & $\begin{array}{l}\text { Professor na escola diferenciada } \\
\text { indígena. }\end{array}$ \\
\hline N (P4) & $\begin{array}{l}\text { Amambai } \\
\text { Amambai }\end{array}$ & Masculino & $\begin{array}{l}\text { Professor nas séries iniciais da } \\
\text { escola diferenciada indígena } \\
\text { ministra aula à estudante surda } \\
\text { usuária de aparelho auditivo }\end{array}$ \\
\hline $\mathrm{Z}(\mathrm{P} 5)$ & $\begin{array}{c}\text { Coronel Sapucaia } \\
\text { Taquaperi }\end{array}$ & Feminino & $\begin{array}{l}\text { Professor nas séries iniciais da } \\
\text { escola diferenciada indígena } \\
\text { ministra aula ao estudante surdo }\end{array}$ \\
\hline $\mathrm{M}(\mathrm{C} 1)$ & $\begin{array}{l}\text { Amambai } \\
\text { Amambai }\end{array}$ & Feminino & $\begin{array}{l}\text { Coordenadora pedagógica na } \\
\text { escola diferenciada indígena }\end{array}$ \\
\hline A (C2) & $\begin{array}{c}\text { Coronel Sapucaia } \\
\text { Taquaperi }\end{array}$ & Masculino & $\begin{array}{l}\text { Coordenador pedagógico na escola } \\
\text { diferenciada indígena. }\end{array}$ \\
\hline $\mathrm{N}(\mathrm{C} 3)$ & $\begin{array}{c}\text { Coronel Sapucaia } \\
\text { Taquaperi }\end{array}$ & Feminino & $\begin{array}{l}\text { Coordenadora pedagógica das } \\
\text { escolas diferenciadas indígenas do } \\
\text { município }\end{array}$ \\
\hline$C(D)$ & $\begin{array}{c}\text { Coronel Sapucaia } \\
\text { Taquaperi }\end{array}$ & Masculino & $\begin{array}{l}\text { Diretor da escola diferenciada } \\
\text { indígena }\end{array}$ \\
\hline $\mathrm{A}(\mathrm{Pi})$ & Amambai & Feminino & Professora Intérprete de LIBRAS \\
\hline $\mathrm{G}(\mathrm{V})$ & $\begin{array}{c}\text { Coronel Sapucaia } \\
\text { Taquaperi }\end{array}$ & Masculino & $\begin{array}{l}\text { Vereador do município, já exerceu } \\
\text { papel de liderança na aldeia. }\end{array}$ \\
\hline
\end{tabular}




\begin{tabular}{|c|c|c|c|}
\hline $\begin{array}{c}\text { Inicial do } \\
\text { Nome/Código }\end{array}$ & $\begin{array}{c}\text { Município/ } \\
\text { Aldeia }\end{array}$ & Sexo & Informações Relevantes \\
\hline R (AS1) & $\begin{array}{c}\text { Amambai } \\
\text { Amambai }\end{array}$ & Masculino & Agente de saúde indígena \\
\hline S (AS2) & $\begin{array}{c}\text { Coronel Sapucaia } \\
\text { Taquaperi }\end{array}$ & Feminino & Agente de saúde indígena \\
\hline
\end{tabular}

Quadro 2 - Identificação dos profissionais que atuam com pessoas surdas nas aldeias.

Fonte: COELHO, 2011.

O contato entre o professor indígena ouvinte e estudante indígena surdo restringe-se à comunicação básica dentro da sala de aula. Da mesma forma como as dificuldades aparecem no ambiente familiar, no ambiente escolar também os professores sentem que os recursos para transmissão dos saberes ao estudante estão limitados pela barreira linguística. Nas narrativas dos professores, percebe-se a angústia por não poderem estabelecer um diálogo com esses jovens:

Eu fiquei assim, totalmente desacorçoado, né, perante elas, sem poder ajudar. (P1)

Eu trabalhei no computador, trabalhei no desenho, eu não sei, ele se sentia assim, isolado dos outros, não conversava com ninguém. (P3)

Quando acontece isso na sala, a gente não sabe como lidar com essas pessoas (P3)

Os professores reconhecem que existem leis que garantem o direito à educação para essas pessoas (BRASIL, 2008) e relatam que utilizar estratégias como figuras, imagens e desenhos, facilita o processo de ensino-aprendizagem. Percebe-se que muitos deles não conhecem a língua de sinais e os recursos indicados para o ensino de pessoas surdas, cujas estratégias consistem na superação das dificuldades de comunicação. Os professores reconhecem que parte dessa dificuldade está em sua formação (ou na falta de formação específica). Alguns admitem não terem percebido a dificuldade dos estudantes:

Ninguém percebe que ela é assim, porque ela entende bem o que a gente fala pra ela e responde o que pergunta. (C.)

Até metade do ano não sabia que ela usava aparelho, porque ela presta atenção. Mas hoje a gente tem que colocar ela na frente (P4)

Percebe-se nessas falas que alguns desconhecem as barreiras enfrentadas pelos alunos; alegam que a dificuldade é imperceptível e que algumas providências só foram tomadas após o pedido de outros profissionais da escola. O desconhecimento da língua de sinais e outros recursos pedagógicos por parte dos professores é o que mais dificulta a interação dos jovens que utilizam sinais dentro da sala de aula. 
Outro problema observado pela professora intérprete de LIBRAS (Pi) é a complexidade linguística do ambiente educacional das escolas indígenas. Os estudantes aprendem a fazer a leitura labial de palavras oralizadas por seus familiares em língua guarani ou kaiowá, e, quando vão para a escola, têm contato com professores que ministram as aulas em língua portuguesa. Observamos isso no relato a seguir:

O A. só sabia algumas palavras em guarani e eu não sabia nada dessa língua. Nas aulas ministradas em português, eu sinalizava em LIBRAS, e o aluno visivelmente não compreendia nenhuma dessas línguas. (Pi)

Percebe-se que, nas escolas indígenas, ainda existem muitos professores não indígenas falantes da língua portuguesa que ministram aulas de matérias diversas. Sobre esse assunto, as gestoras da educação nos municípios alegam que faltam professores indígenas capacitados para o ensino de crianças e jovens nas escolas das aldeias e, por esse motivo, necessita-se contratar profissionais não indígenas. A própria língua materna da população indígena fica em um segundo plano ou, como explica Nascimento (2003, p. 42), ela é utilizada como “[...] ponte, língua de transição, de facilitação, para a compreensão do conteúdo dominante e para diminuir o índice de fracasso expresso pela repetência e evasão". Vê-se que a questão é complexa, uma vez que envolve crianças e adolescentes em fase de desenvolvimento cognitivo e social, que muitas vezes têm o seu direito linguístico negligenciado em contextos plurilíngues.

Os três estudantes que ainda permanecem frequentando a escola foram observados em suas relações com os colegas. Constatou-se que existe uma boa relação entre todos os estudantes da escola e os jovens, apesar de a comunicação ser limitada pela diferença linguística:

Ele é assim dentro da sala de aula (quieto). Fora da escola ele brinca, conversa com os colegas. Era o aluno mais querido de todos. (P3)

Ela é esperta, aprende fácil e se relaciona bem na sala, faz as atividades, brinca com os menores (P2)

Constata-se que a dificuldade de comunicação não impede que os jovens se relacionem com os colegas e aprendam a realizar tarefas cujos procedimentos eles compreendem. Mas, com o estudante A., a convivência na sala com colegas de idade muito inferior à dele (frequentava o $4^{\circ}$ ano do ensino fundamental) foram determinantes para a escolha de abandonar a escola. Isso significa que, além da barreira linguística, existia ainda a defasagem idadesérie, o que desestimulava o jovem a permanecer em sala de aula.

Como muitos outros estudantes com deficiência, a falta de recursos humanos capacitados para o atendimento e a falta de recursos físicos e materiais que permitam a aprendizagem desses alunos fazem com que eles permaneçam retidos em salas de aula do ensino fundamental. Nesse contexto, os professores se veem diante de um dilema: reter o aluno em séries iniciais ou permitir que 
ele ascenda a níveis mais avançados, mesmo que não domine os conteúdos mínimos exigidos para isso?

A proposta de educação bilíngue para as pessoas surdas deve ser oferecida desde os anos iniciais. No documento Política de Educação Especial na Perspectiva da Educação Inclusiva (BRASIL/MEC, 2008), a educação bilíngue é definida como o ensino escolar na língua portuguesa e na língua de sinais, sendo a língua portuguesa ensinada como segunda língua na modalidade escrita para alunos surdos. Há também a recomendação da oferta de serviços de tradutor/intérprete de libras e língua portuguesa e o ensino da LIBRAS para os demais alunos da escola. $\mathrm{O}$ atendimento educacional especializado deve ser ofertado tanto na modalidade oral e escrita quanto na língua de sinais. Devido à diferença linguística, na medida do possível, o aluno surdo deve estar com outros pares surdos em turmas comuns na escola regular (BRASIL, 2008), para permitir a identificação linguística e cultural entre essas pessoas.

Diante dessa proposta, os professores e a escola indígena enfrentam o desafio de organizar e oferecer essa modalidade de ensino na escola diferenciada, onde o ensino já é ministrado em duas línguas (língua guarani e língua portuguesa) e onde faltam profissionais capacitados para esse atendimento. Outro problema é o isolamento social em que vivem as pessoas surdas nas comunidades, o que não tem permitido o desenvolvimento de uma língua de sinais própria dos indígenas pertencentes ao grupo Guarani-Kaiowá.

Os surdos que permanecem na escola estão inseridos em salas de aula comuns, nas quais os professores e os colegas são falantes da língua oral da comunidade (língua guarani). Nessas escolas, não há profissionais intérpretes de língua de sinais (que também estão em número reduzido nas escolas da zona urbana dos municípios) e o recurso do Atendimento Educacional Especializado (AEE) não é ofertado aos alunos.

Observa-se que as adequações recomendadas pela política de educação especial não são aplicadas na escola diferenciada indígena, pois a proposta bilíngue para a educação de surdos é desconhecida por essa população. Verifica-se nas falas dos professores indígenas que a maioria possui pouco ou nenhum conhecimento das estratégias pedagógicas e da condição linguística dos surdos. Os professores P1 e P2 comentam sobre o despreparo para lidar com a situação e a falta de apoio da secretaria de educação do município:

É eu já tive [alunos surdos] em outras situações, mas eu tive mais apoio. (P1)

Eu acho que eles [a Secretaria de Educação do município] nem sabem que tem essa criança aqui, acho que eles nem sabem. (P2)

No relato do professor P1, percebe-se que ele se sente despreparado para ensinar as pessoas surdas, e a professora P2 diz não receber apoio da secretaria de educação do seu município, tanto no que diz respeito à oferta 
de recursos e formação continuada aos professores quanto no acompanhamento do atendimento às necessidades específicas da aluna. As estratégias utilizadas por esses profissionais são baseadas na observação das facilidades e dificuldades dos alunos no desenvolvimento das atividades em sala de aula.

Todos os professores entrevistados concordam que os alunos possuem capacidade para aprender, apesar da dificuldade linguística. Relatam utilizar imagens e figuras com o objetivo de permitir a compreensão dos conteúdos pelos alunos, porém acreditam não ser suficiente tal adequação, pois a escola carece de recursos e estruturas básicas.

Em face desses relatos, percebe-se que as escolas indígenas estão diante de um desafio: preparar-se para receber as pessoas com deficiência/ diferença linguística em seu espaço de aprendizagem comum. Nessas escolas, a construção de um espaço inclusivo de respeito à diversidade presente nas comunidades indígenas só pode e deve ser feita por meio da atuação (e com a participação) dos próprios indígenas. O reconhecimento dos saberes tradicionais, da língua e da cultura não é suficiente para que a escola seja indígena. É preciso que as metodologias e os modos de gestão educacional sejam pensados e executados pela própria comunidade, como defendido por C. no trecho abaixo:

A gente não encontra um mecanismo próprio nosso pra proteger essas famílias que têm essas necessidades, essas dificuldades [famílias das pessoas com deficiência]. Nós mesmos, como povo Guarani-Kaiowá, a gente não encontra um jeito tradicional, porque isso não está sendo mais respeitado [...] e também um modo de adequar o conhecimento que é nosso com o conhecimento dos não índios. Vocês têm uma forma de tratar, de ter esse espaço, mas que não seja totalmente como vocês criam, né, tem que ter um meio nosso ali, com o nosso jeito. (D)

As recomendações dos textos legais que organizam a oferta da educação especial nas instituições de ensino muitas vezes são percebidas como imposições da cultura urbana. No relato desse profissional indígena, percebemos que as mudanças que estão acontecendo nas aldeias e problemas decorrentes dela são explicados pela interferência dos não índios na cultura da comunidade.

Diante disso, cabe aos gestores da educação dos municípios proporcionarem espaços de diálogo junto aos profissionais indígenas, para que a questão da inclusão educacional das pessoas surdas e com deficiências diversas seja discutida. Além disso, urge a necessidade de se elaborar um plano de ação por esses profissionais para atuação junto às pessoas com deficiência, para que elas saiam da condição de pessoas invisíveis dentro da comunidade para a condição de cidadãos. 


\section{Considerações finais}

Os estudos culturais forneceram suporte teórico para pensarmos a constituição dos sujeitos surdos a partir das relações simbólicas e compreender os processos culturais, linguísticos, políticos e sociointerativos para as estratégias de participação e de sobrevivência desses indivíduos nas aldeias onde habitam.

Ao longo da pesquisa, identificamos as especificidades dos povos Guarani-Kaiowá, sua história, o conjunto de significações, crenças e práticas que compõem a identidade ou o modo de ser Guarani. Em nossa investigação, compreendemos que a cultura desses povos tem suas raízes nas histórias, mitos e crenças passadas de geração a geração, na língua que é compartilhada pelo grupo e nas práticas religiosas.

Em relação aos depoimentos dos familiares, observou-se que essas pessoas desconhecem as possibilidades da pessoa surda, bem como não sabem lidar com as especificidades da comunicação visual. Apesar de conviverem no ambiente familiar de maneira natural, com participação na rotina familiar, percebemos que a falta de orientação sobre a surdez limita o desenvolvimento de estratégias para a comunicação e interação nesse ambiente.

Nas escolas diferenciadas indígenas, alguns dos jovens surdos frequentam as aulas, interagem e comunicam-se com os colegas ouvintes, apesar de existir uma barreira linguística. O relacionamento com os professores também acontece de forma satisfatória, embora restrito pela ausência de estratégias de comunicação.

Os profissionais da educação apontam que existem alguns problemas para se efetivar a inclusão de pessoas com deficiência, como a falta de formação específica; a falta de comunicação entre os profissionais da rede; a falta de apoio para a elaboração de estratégias de ensino que respeitem a metodologia de ensino dos povos indígenas; a falta de recursos materiais e pedagógicos; a dificuldade para se efetivar o atendimento educacional especializado nas escolas indígenas, entre outros. Nesse contexto, percebe-se que os dispositivos legais que reconhecem a diferença linguística das pessoas surdas e organizam o ensino escolar adequado às especificidades dessas pessoas não são aplicados nas escolas indígenas.

O contexto linguístico dessas escolas diferenciadas também é complexo. Em muitos momentos, a compreensão dos conteúdos requer o domínio de duas línguas (língua guarani e língua portuguesa), o que dificulta o processo de ensino/aprendizagem para muitas crianças e adolescentes indígenas. A situação pode se agravar com a inclusão de mais uma língua no contexto escolar (a LIBRAS). Porém, com a análise das estratégias utilizadas pelos surdos para se comunicarem, acredita-se que o ensino e a difusão de uma língua de sinais que considere as particularidades da comunicação dos surdos da 
comunidade indígena pode ser uma ferramenta emergencial de empoderamento desse grupo.

Com a aprendizagem e o domínio de uma língua de sinais, o indígena surdo poderá 'falar' e 'ser ouvido' nessa cultura, assim como criar espaços de pertença e participação social, alcançar níveis de compreensão mais elevados da realidade e comunicar-se entre si e com a comunidade em geral. Uma língua de sinais compreendida por todos os surdos indígenas da comunidade permitirá o diálogo dentro do grupo, o que futuramente poderá contribuir com o processo de identificação dos sinais próprios das comunidades e convencioná-los em uma língua.

\section{Referências}

BRASIL. Política Nacional de Educação Especial na perspectiva da Educação Inclusiva. MEC-SEESP, Brasília: 2008. Disponível em http:// portal.mec.gov.br/seesp/arquivos/ pdf/politica.pdf>. Acesso em: 12 mar. 2011.

CÁRIA, T. H. Experiência etnográfica em Ciências sociais. Portugal: Edições Afrontamento, 2004

CHAMORRO, G. Terra madura, yoy araguyje: fundamento da palavra guarani. Dourados, MS: Editora da UFGD, 2008.

COELHO, L. L. A constituição do sujeito surdo na cultura Guarani-kaiowá: os processos próprios de interação e comunicação na família e na escola. 2011. Dissertação (Mestrado em Educação) - Programa de Pós-Graduação em Educação da Universidade Federal da Grande Dourados, Dourados.

GRUPIONI, L. D. B. Olhar longe porque o futuro é longe: cultura, escola e professores indígenas no Brasil. São Paulo, 2008. Tese (Doutorado em Antropologia Social) Faculdade de Filosofia, Letras e Ciências Humanas da Universidade de São Paulo.

HALL, S. A identidade cultural na pós-modernidade. Tradução de Tomaz Tadeu da Silva e Guacira Lopes Louro. 11. ed. Rio de Janeiro: DP\&A Editora, 2006.

MELIÁ, B. Teko Porã: modo de vida Guarani. Palestra proferida na UFGD, Dourados, 08 de abril de 2011.

NASCIMENTO, A. C. Língua Indígena na escola: recolonização ou autonomia? Série Estudos - Periódico do Programa de Pós-Graduação em Educação da UCDB, Campo Grande, n. 15, p. 39-47, jun. 2003.

NASCIMENTO, A. C.; VINHA, M. Educação escolar indígena e o sistema nacional de educação. In: SIMPÓSIO BRASILEIRO DE POLÍTICA E ADMINISTRAÇÃO DA EDUCAÇÃO, XXIII.; CONGRESSO LUSO-BRASILEIRO DE POLÍTICA E ADMINISTRAÇÃO DA EDUCAÇÃO, V.; COLÓQUIO IBERO-AMERICANO DE POLÍTICA E ADMINISTRAÇÃO ANPAE, I., 11-14 nov. 2007, Porto Alegre. Caderno de resumos... Disponível em: <http://www.anpae.org.br/congressos_antigos/simposio2007/01. pdf>. Acesso em: ago. 2011.

Tellus, ano 13, n. 25, jul./dez. 2013 
QUADROS, R. M.; KARNOPP, L. Lingua de sinais brasileira: estudos lingüísticos. Porto Alegre: ARTMED, 2004.

QUADROS, R. M. Educação de surdos: a aquisição da linguagem. Porto Alegre: ARTMED, 1997.

SKLIAR, C. (Org.). Atualidade da educação bilíngüe para surdos: processos e projetos pedagógicos. 3. ed. Porto Alegre: Mediação, 2009. guarani-kaiowá: os processos próprios de interação e comunicação na família e na escola 